\title{
A cluster randomised controlled trial of smoking cessation in pregnant women comparing interventions based on the transtheoretical (stages of change) model to standard care
}

\author{
T Lawrence, P Aveyard, O Evans, K K Cheng
}

Tobacco Control 2003;12:168-177

See end of article for authors' affiliations

Correspondence to: Terry Lawrence, The Department of Public Health and Epidemiology, University of Birmingham Birmingham B15 2T, UK p.t.lawrence@bham.ac.uk

Received 19 April 2002. Accepted

29 November 2002
Objectives: To evaluate the effectiveness in helping pregnant women stop smoking of two interventions (Pro-Change for a healthy pregnancy) based on the transtheoretical model of behaviour change (TTM) compared to current standard care.

Design: Cluster randomised trial.

Setting: Antenatal clinics in West Midlands, UK general practices.

Participants: 918 pregnant smokers

Interventions: 100 general practices were randomised into the three trial arms. Midwives in these practices delivered three interventions: A (standard care), B (TTM based self help manuals), and C (TTM based self help manuals plus sessions with an interactive computer program giving individualised smoking cessation advice).

Main outcome measures: Biochemically confirmed smoking cessation for 10 weeks previously, and point prevalence abstinence, both measured at 30 weeks of pregnancy and 10 days after delivery. Results: There were small differences between the TTM arms. Combining the two arms, the odds ratios at 30 weeks were 2.09 (95\% confidence interval (Cl) 0.90 to 4.85 ) for 10 week sustained abstinence and $2.92(95 \% \mathrm{Cl} 1.42$ to 6.03$)$ for point prevalence abstinence relative to controls. At 10 days after delivery, the odds ratios were $2.81(95 \% \mathrm{Cl} 1.11$ to 7.13$)$ and $1.85(95 \% \mathrm{Cl} 1.00$ to 3.41$)$ for 10 week and point prevalence abstinence respectively.

Conclusions: While there is a small borderline significant increase in quitting in the combined intervention arms compared with the controls, the effect of the intervention is small. At 30 weeks gestation and at 10 days postnatal, only about $3 \%$ of the intervention groups achieved sustained cessation, with numbers needed to treat of 67 ( 30 weeks of gestation) and 53 (10 weeks postnatal) for one additional woman to achieve sustained confirmed cessation. Given also that the intervention was resource intensive, it is of doubtful benefit.
$\mathrm{T}$ he earlier in pregnancy that women stop smoking, the greater the benefit to their fetus. ${ }^{1}$ About $25 \%$ of women who smoke stop before or early in pregnancy ${ }^{2}$; thereafter the incidence of smoking cessation in pregnancy is low, with the majority of women who do stop smoking doing so in the first trimester. ${ }^{4}$ The quality of evidence is varied, and studies indicate rates of between $-2 \%{ }^{5}$ and $20 \%{ }^{6}$ cessation can be achieved by delivering smoking cessation interventions during pregnancy. Midwives are the main group delivering smoking cessation advice to pregnant women. Despite recent evidence that brief counselling intervention delivered by a trained smoking cessation specialist together with pregnancy specific self help materials significantly increases cessation, ${ }^{17-9}$ other studies give no reason for confidence that information delivered by midwives about smoking in pregnancy encourages women to quit. ${ }^{310-13}$ Lack of time and competence are reasons commonly given for this failure. ${ }^{13}{ }^{14}$ Midwives continue to provide smoking cessation advice despite their ineffectiveness because there is no one else to do this.

An alternative to midwives' advice is the Pro-Change self help system. Women complete a questionnaire on their thoughts and feelings about smoking. Using this, computerised decision rules create individualised smoking cessation strategies that assist women to move closer to stopping, stop, and stay stopped. The system is backed up by a self help manual. There is some evidence that the Pro-Change system has a small effect in non-pregnant adults, ${ }^{15-18}$ but is ineffective in children. ${ }^{19}{ }^{20}$ The aim of this study was to examine its effectiveness in smoking cessation in pregnancy relative to standard care offered by midwives.

\section{METHOD}

\section{Participants}

We aimed to examine the effectiveness of the intervention in a representative sample of community midwives and pregnant women because this was a pragmatic trial. ${ }^{21}$ Accordingly, we asked the head midwife in every trust in the West Midlands region of the UK to participate. Three of the 19 declined. Each participating trust supplied us with a list of general practices, from which we randomly selected 204 potential practices. The head midwife in each trust excluded 103 practices. The main reasons were that the community midwife was already involved in other research, or that the general practice catchment area crossed trust boundaries. Seventy two practices were needed, and they were randomly sampled from the 101 remaining practices. Sometimes two or occasionally more midwives served one practice, but no midwives served more than one practice included in this sample.

In participating practices, community midwives were asked to recruit all eligible women seen in routine antenatal appointments. A woman was eligible if she was aged 16 or over, pregnant, and a current smoker at booking. Funding did 
not permit the cost of translation of the intervention materials from English to other languages, so pregnant smokers who did not consider themselves fluent in spoken or written English were excluded.

\section{Interventions}

In this pragmatic trial, ${ }^{21}$ we examined the relative effectiveness of three interventions: arm A, controls; arm B, manuals; and arm C, computer. Midwives in each trial arm were aware that they were one of three trial arms.

\section{Arm A: controls}

The intervention in arm A was intended to be standard smoking cessation advice given by midwives, who would have variable training and variable skills. This is consistent with our intention to pursue a pragmatic trial design. ${ }^{21}$ Midwives in arm A received half a day's training on the research protocol only. They were asked to deliver smoking cessation advice as they would normally do. Some arm A midwives might have received training on the stages of change in other contexts and might therefore have used a stage based approach. The only attempt to standardise the intervention was that we asked all midwives in this arm to give women the Health Education Authority booklet Thinking about stopping. This three page leaflet gives advice on how to stop smoking and was routinely used by midwives in all participating trusts anyway. Following this training, midwives were asked to practice recruiting and familiarising themselves with the trial material. Midwives reconvened for half a day's reflection to check that they were comfortable with the details of the trial protocol and aspects of consent.

\section{Arm B: manuals}

Midwives in arm $\mathrm{B}$ received two and a half days training. Two days training on the theory of the transtheoretical model (TTM) was provided by Public Management Associates, who hold the UK licence for the interventions. This consisted of one and a half days training on the concepts of the TTM and familiarisation with the stage based manuals. The research team at the University of Birmingham provided half a day's training on research protocol, as for arm A. Following this, midwives practised recruiting women and using the materials and then had a half day's reflective session on their experiences and for them to recheck details of the intervention.

Participants recruited to trial arm B received a set of six, 30 page stage based self help manuals Pro-Change programme for a healthy pregnancy. The set consisted of one manual for each stage of change and a further one for "recycling". These manuals explained the concepts of stage of change, helped participants to stage themselves, and contained quizzes and exercises to engage the stage appropriate processes of change. Additionally, at each of three occasions during pregnancy, $<20$ weeks; 23-25 weeks; and 28-30 weeks, the midwife assessed a participant's stage of change, pointed the woman to the appropriate manual in the stage series, and spent no more than 15 minutes ensuring that the participant was familiar with how to use the materials by going through an appropriate exercise with her and discussing it.

\section{Arm C: computer}

The midwives in this arm received the same training as midwives in arm B. The participants also received the same stage based, self help manual intervention as arm $\mathrm{B}$ and the midwife explained how to use the stage based manuals in the same way. Additionally, these participants used a computer programme installed on a laptop computer on each of the three intervention occasions (as in arm B). Women worked alone without the midwife using the computer program. This consisted of questions to stage the woman, and this was followed by on-screen and audio feedback of what stage women were in and what that meant. This format was repeated for the other concepts: decisional balance, temptation, and processes of change, with strategies to use to move stage. It took about 20 minutes to complete. On second and third use, women also received feedback on progress or lack of it since the last use. Following each use of the computer, the feedback was printed out and sent to the participant within one week of the intervention.

\section{Outcomes}

The two primary outcomes were confirmed point prevalence of smoking cessation and confirmed* sustained abstinence assessed at 28-30 weeks and 10 days postnatally. The results are presented as point prevalence of quitting and sustained abstinence of 10 weeks or more. Sustained abstinence is the only outcome that is likely to benefit the fetus. Point prevalence is important because it captures women stopping smoking late in pregnancy after moving through the stages of change. It is therefore theoretically appropriate, and it may indicate that these women might still be stopped in the future. We also pre-specified that we would combine the two stages of change arms to compare their effectiveness relative to $\operatorname{arm} \mathrm{A}$.

Information on women's social characteristics, smoking habits, and stage of change was collected at the three research visits and once more 10 days after delivery by self completion paper questionnaires and by computerised questionnaire in arm C. Self reported point prevalence smoking cessation was defined by responses to the question "How many cigarettes do you normally smoke in a day?" where the response "I have given up" was expected. Additionally, women had to have smoked no cigarettes in the past 24 hours and to have reported consistent smoking status on the staging questions included in a second questionnaire completed at the same time. For 10 week continuous abstinence, women had to report no cigarette in the past 10 weeks. We confirmed smoking cessation status by urinary cotinine because women routinely give urine samples in pregnancy care and it is as valid an indicator of the presence of nicotine as serum or saliva. ${ }^{22}$ Urine was analysed by the Wolfson Laboratories, Birmingham University, using a colorimetric assay. ${ }^{23}$ We assumed that those who reported continuing smoking regardless of cotinine level, those who did not provide samples, or whose cotinine values were above $1.5 \mu \mathrm{g} / \mathrm{l}$, were still smoking.

The effect of training the midwives was assessed by questionnaires completed before and after the training courses. Information was collected about midwives' attitudes and routine practice on smoking in pregnancy, their expectations of the interventions they would deliver, and their confidence and concerns about carrying out the research protocols.

\section{Sample size}

Initially we aimed to recruit 1440 participants, but the target was reduced to 900 because of slow recruitment. We assumed that $8 \%$ of the controls ( $a r m \mathrm{~A}$ ) would quit, the average in the relevant Cochrane review. ${ }^{1}$ This gave $80 \%$ power to detect an odds ratio of 2.2 for differences between the control and intervention arms, with a type I error of 0.05, accounting for clustering using a published intraclass correlation coefficient from a similar trial. ${ }^{24}$ Research by Prochaska and colleagues shows that use of the stage based system produces quit rates of $18-25 \%$ in unselected smokers at 18 months, ${ }^{25} 26$ implying odds ratios greater than we had the power to detect.

We always planned to conflate arms $\mathrm{B}$ and $\mathrm{C}$ to compare them against arm A. Such a comparison with the above assumptions gives $80 \%$ power to detect odds ratios of 2.00 .

*By confirmed, we mean in all cases that a single specimen of urine at that time point revealed a cotinine level below the threshold. 


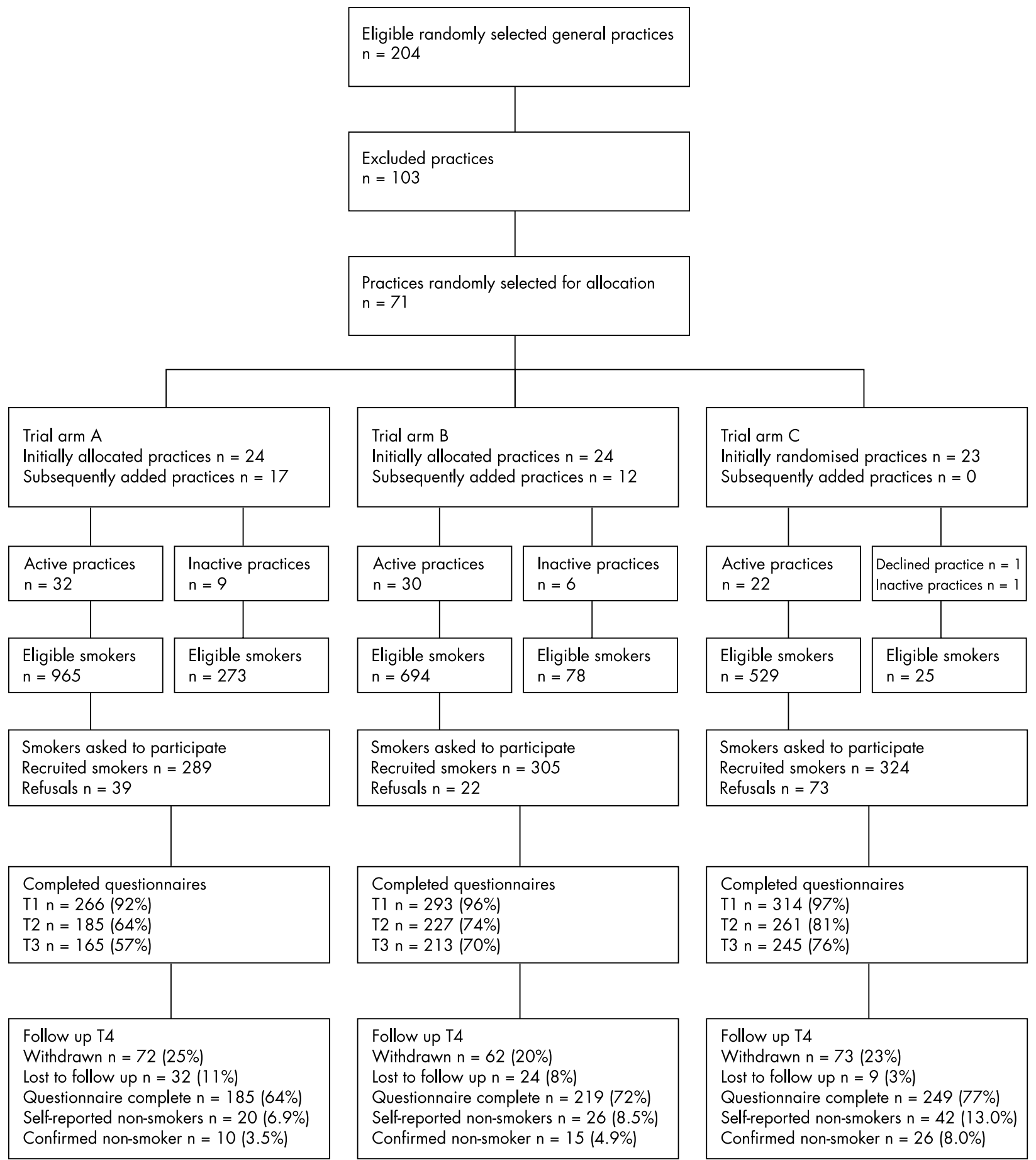

Figure 1 Flow of participants through the trial.

\section{Randomisation}

A computerised minimisation programme was used to allocate 72 eligible practices into three equal groups from the 101 available practices. We ensured that the likelihood of stopping smoking for women recruited into each arm of the trial was similar by taking account of the characteristics of the population that each midwife served in the allocation. The minimisation variables were the mean Townsend score of each practice's patients (four groups), urban/rural distribution (two groups), and birth rate (three groups).

Recruitment, particularly to the standard care arm of the trial, was slower than predicted. Nine months into the study, a further 17 general practices, from the original list of 101 avail- able practices, were added to arm A. Twelve midwives in arm B were recruited from an additional "buddy" practice in which they were already holding antenatal clinics, but which had not been randomly selected initially.

\section{Statistical methods}

Random effects logistic regression was used to calculate the odds of smoking cessation by arm using MLwiN (multi-level modelling for Windows).$^{27}$ Practice was entered as a random effect to account for allocation by practice, rather than individual patient. The results are presented as percentages, which are calculated with the random effect set to zero, and 
Table 1 Baseline characteristics of participants by trial arm

\begin{tabular}{|c|c|c|c|c|c|c|}
\hline & \multicolumn{2}{|l|}{ Arm A } & \multicolumn{2}{|l|}{ Arm B } & \multicolumn{2}{|l|}{ Arm C } \\
\hline & Count & Col \% & Count & Col \% & Count & Col \% \\
\hline \multicolumn{7}{|l|}{ Cigarettes per day at baseline } \\
\hline Unknown & 21 & 7.3 & 12 & 3.9 & 19 & 5.9 \\
\hline$<5$ & 49 & 17.0 & 67 & 22.0 & 38 & 11.7 \\
\hline $5-9$ & 106 & 36.7 & 106 & 34.8 & 117 & 36.1 \\
\hline $10-19$ & 90 & 31.1 & 103 & 33.8 & 128 & 39.5 \\
\hline $20-29$ & 19 & 6.6 & 15 & 4.9 & 21 & 6.5 \\
\hline $30+$ & 4 & 1.4 & 2 & 0.7 & 1 & 0.3 \\
\hline \multicolumn{7}{|l|}{ Weeks gestation at enrolment } \\
\hline Median (10th, 90th centile) & 11.7 & $(7.1,18.9)$ & 11.9 & $(8.0,18.7)$ & 13.0 & $(7.4,19.0)$ \\
\hline \multicolumn{7}{|l|}{ Ethnic group } \\
\hline DK & 28 & 9.7 & 16 & 5.2 & 23 & 7.1 \\
\hline Black African & 1 & 0.3 & 0 & 0.0 & 0 & 0.0 \\
\hline Black Caribbean & 0 & 0.0 & 8 & 2.6 & 4 & 1.2 \\
\hline Black other & 2 & 0.7 & 2 & 0.7 & 0 & 0.0 \\
\hline Indian & 2 & 0.7 & 0 & 0.0 & 1 & 0.3 \\
\hline Mixed & 4 & 1.4 & 3 & 1.0 & 3 & 0.9 \\
\hline Pakistani & 0 & 0.0 & 2 & 0.7 & 0 & 0.0 \\
\hline White & 250 & 86.5 & 273 & 89.5 & 292 & 90.1 \\
\hline Mixed & 2 & 0.7 & 1 & 0.3 & 1 & 0.3 \\
\hline \multicolumn{7}{|l|}{ Parity } \\
\hline Missing & 26 & 9.0 & 14 & 4.6 & 21 & 6.5 \\
\hline Nulliparous & 92 & 31.8 & 120 & 39.3 & 118 & 36.4 \\
\hline Multiparous & 171 & 59.2 & 171 & 56.1 & 185 & 57.1 \\
\hline \multicolumn{7}{|l|}{$\begin{array}{l}\text { Has a } \\
\text { partner }\end{array}$} \\
\hline DK & 22 & 7.6 & 10 & 3.3 & 18 & 5.6 \\
\hline No partner & 21 & 7.3 & 22 & 7.2 & 32 & 9.9 \\
\hline Has partner & 246 & 85.1 & 273 & 89.5 & 274 & 84.6 \\
\hline \multicolumn{7}{|l|}{ Partner smokes } \\
\hline DK or no partner & 24 & 8.3 & 12 & 3.9 & 19 & 5.9 \\
\hline Does not smoke & 84 & 29.1 & 87 & 28.5 & 119 & 36.7 \\
\hline Smokes & 181 & 62.6 & 206 & 67.5 & 186 & 57.4 \\
\hline \multicolumn{7}{|l|}{ Other smokers in household } \\
\hline Missing & 117 & 40.5 & 102 & 33.4 & 122 & 37.7 \\
\hline No other smokers & 130 & 45.0 & 144 & 47.2 & 153 & 47.2 \\
\hline Other smokers & 42 & 14.5 & 59 & 19.3 & 49 & 15.1 \\
\hline \multicolumn{7}{|l|}{ Highest education } \\
\hline DK & 66 & 22.8 & 62 & 20.3 & 78 & 24.1 \\
\hline Degree & 3 & 1.0 & 7 & 2.3 & 4 & 1.2 \\
\hline A-levels & 30 & 10.4 & 39 & 12.8 & 25 & 7.7 \\
\hline O-levels & 86 & 29.8 & 103 & 33.8 & 92 & 28.4 \\
\hline None & 60 & 20.8 & 69 & 22.6 & 75 & 23.1 \\
\hline Other & 44 & 15.2 & 25 & 8.2 & 50 & 15.4 \\
\hline \multicolumn{7}{|l|}{ Weekly income $(£)$} \\
\hline DK & 39 & 13.5 & 19 & 6.2 & 40 & 12.3 \\
\hline$<100$ & 53 & 18.3 & 70 & 23.0 & 70 & 21.6 \\
\hline $100-200$ & 76 & 26.3 & 84 & 27.5 & 76 & 23.5 \\
\hline $200-300$ & 55 & 19.0 & 55 & 18.0 & 61 & 18.8 \\
\hline $300-400$ & 34 & 11.8 & 41 & 13.4 & 44 & 13.6 \\
\hline $400+$ & 32 & 11.1 & 36 & 11.8 & 33 & 10.2 \\
\hline \multicolumn{7}{|l|}{ Baseline stage } \\
\hline Missing & 43 & 14.9 & 22 & 7.2 & 90 & 27.8 \\
\hline Precontemplation & 77 & 26.6 & 57 & 18.7 & 42 & 13.0 \\
\hline Contemplation & 113 & 39.1 & 139 & 45.6 & 127 & 39.2 \\
\hline Preparation & 56 & 19.4 & 87 & 28.5 & 65 & 20.1 \\
\hline Age band (years) & & & & & & \\
\hline DK & 53 & 18.3 & 23 & 7.5 & 32 & 9.9 \\
\hline Under 20 & 32 & 11.1 & 45 & 14.8 & 52 & 16.0 \\
\hline $20-29$ & 134 & 46.4 & 160 & 52.5 & 172 & 53.1 \\
\hline $30+$ & 70 & 24.2 & 77 & 25.2 & 68 & 21.0 \\
\hline Fagerstrom test for nicotine dependences* & & & & & & \\
\hline Median (10th and 90th centile) & 3 & $(0-6)$ & 3 & $(0-6)$ & 3 & $(0-6)$ \\
\hline Age at enrolment† & & & & & & \\
\hline Median (10th and 90th centile) & 26.7 & (19.3-34.2) & 26.3 & $(18.7-35.3)$ & 25.4 & $(18.7-34.0)$ \\
\hline
\end{tabular}

may not correspond with the raw percentage. We also prespecified that we would adjust for potential predictors of smoking cessation that might differ between the arms, described in table 1. It was done using the same logistic regression methods as above, but including all variables in table $\mathrm{l}$ as dummy terms. We also conflated arms B and C and compared the relative effectiveness of this combined arm to arm A (control) using the same methods as above.
Ethical approval

The trial received ethical approval from the multicentre and local research ethics committees.

RESULTS

Participant flow

Of the 72 originally allocated practices, midwives in one practice in arm C refused to participate. Nine practices in arm A, 
Table 2 Baseline characteristics of midwives

\begin{tabular}{llll}
\hline & Arm A & Arm B & Arm C \\
\hline Feel smoking cessation advice part of job, median (10th, 90th centile) & $4(2,4)$ & $4(3,4)$ & $3(3,4)$ \\
Concern about level of smoking, median (10th, 90th centile) & $3(1,4)$ & $3(2,4)$ & $3(2,4)$ \\
Length of time a community midwife, median (10th, 90th centile) & $10(3,20)$ & $9(2,28)$ & $4(1,18)$ \\
\% smokers expect to give up during pregnancy, median (10th, 90th & $10(2,50)$ & $10(3,62)$ & $20(6,50)$ \\
centile) & $55(18)$ & $77(20)$ & $61(20)$ \\
\% asking about smoking every time (mean (SD)) & $52(17)$ & $72(18)$ & $52(17)$ \\
\% giving written material (mean (SD)) & $82(27)$ & $89(23)$ & $84(27)$ \\
\% having previous training re HP and pregnancy (mean (SD)) & $58(19)$ & $62(16)$ & $67(22)$ \\
\% Having previous training re-smoking and pregnancy (mean (SD)) & $42(14)$ & $43(12)$ & $42(15)$ \\
\% Having previous training on TTM (mean (SD)) & & & \\
\hline TMM, transtheoretical model. & & &
\end{tabular}

six practices in arm $\mathrm{B}$, and one in arm $\mathrm{C}$ recruited nobody (fig 1). When asked, midwives in these practices explained that no smokers had booked for maternity care. However, many inactive practices were in one trust serving a socially deprived area, so it is more likely that, for some at least, management issues explained the inactivity.

Midwives were asked to record the number of smokers that they saw that refused trial entry, but they did not do so reliably. We estimated the number of smokers booking in each practice. We calculated each practice's annual birth rate from hospital episode statistics, adjusted for the number of pregnancies ending in miscarriage in the trial to calculate the annual pregnancy rate. We applied this to the period of potential recruitment for each practice, and applied the national prevalence of smoking in pregnancy to calculate the expected number of pregnant smokers seen. ${ }^{28}$ Arm A recruited a minority of all eligible women, whereas arm $\mathrm{C}$ recruited the majority (fig l).

\section{Recruitment}

The originally allocated practices recruited women between July 1998 and May 2000 and were followed up between September 1998 and September 2001 and recruited 799 participants. Practices added subsequently to arm A recruited women between March 1999 and July 2000 and followed them up between October 1999 and February 2001 and recruited 91 participants. Practices added subsequently to arm B recruited women between December 1999 and May 2000 and followed up between May 2000 and March 2001 and recruited 28 participants.

\section{Baseline data}

There was little difference at recruitment between the midwives or recruited women in the three trial arms (tables 1 and 2). Women smokers who refused were staged at booking and then followed up postnatally and smoking status recorded. These data were supplied anonymously to us. The baseline stage distribution of refusers was similar to participants. Although many refusers were lost to follow up, assuming they were smokers, the quit rate was similar (data not shown).

\section{Numbers analysed}

In total, 918 women entered the study and we had self reported smoking status data on $618(67.3 \%)$ women in late pregnancy and $646(70.4 \%)$ women postnatally. This is slightly fewer women than the number completing questionnaires (fig 1) because information on smoking status was occasionally missing or contradictory. Two hundred and seven $(22.5 \%)$ women withdrew from the study. The remainder without follow up data did not complete their questionnaires. The main reasons for withdrawal were 77 women's pregnancy ended early (mainly miscarriage), 38 women changed general practice, 32 women declined further participation, and 60 women left for other reasons, mostly losing contact with the midwife.
Rates of withdrawal and reasons for withdrawal did not differ much by arm, but failure to complete the questionnaire and supply a urine sample did (fig 1). We conducted sensitivity analysis for loss to follow up, assuming that those with missing data were still smoking. Three different denominators were used.

Firstly, we analysed the results with all women who entered the trial in the denominator. This assumes that women who withdrew or women who did not give us data were smokers. This assumption is probably reasonable, because many withdrawals had no contact with the midwife and intervention, and, in many cases, because pregnancy terminated women had little incentive to stop smoking. Similarly, it is common in smoking cessation trials that those who fail to declare their results are almost always continuing smokers. ${ }^{29}$ This result therefore shows the effect of this programme on all women who become pregnant.

Secondly, we included in the denominator all those who did not withdraw, counting only those with missing data as smokers. This is useful because it shows the effect of the intervention on all women who continue their pregnancy, and the benefit to the fetus.

Thirdly, we included in the denominator only those women whose smoking status was known at the appropriate follow up point - that is, late pregnancy or early postnatal. Midwives in the intervention arms ( $\mathrm{B}$ and $\mathrm{C}$ ) had higher rates of follow up. Midwives in arm A seemed not to make an equivalent effort to collect the data and the assumption that all those lost are smokers could be wrong. If this were so, this would bias the results of the above two analyses in favour of arms B and C.

Seventy two practices were initially allocated to the three arms to balance the likelihood of smoking cessation. Extra practices were subsequently and non-randomly allocated to arms $\mathrm{A}$ and $\mathrm{B}$, the additional midwives only knowing their trial arm after agreeing to participate. The data were therefore analysed by including and excluding those women from the additional practices. There were no important differences between the two sets of analyses, so only the results presented with all recruits are reported.

\section{Outcomes}

Process measures

We calculated the change in midwives' understanding and confidence consequent on their training (table 3). Midwives in the TTM arms felt their understanding had increased, and were confident that more smokers would stop as a consequence of them applying the interventions, but there were no big differences between arms B and C. Arm A midwives, however, felt that fewer people were likely to stop smoking as a consequence of their training.

The only other process measure concerns contact rates between the midwife and pregnant women (fig 1). If a questionnaire was completed, this suggests the intervention was delivered in arms A and B, and implies it certainly was in arm $\mathrm{C}$, where the intervention and questionnaire was computerised. 
Table 3 Difference between midwives' post- and pre-training scores *

\begin{tabular}{lllll}
\hline & Arm A & Arm B & Arm C & p Valuef \\
\hline Change in understanding of TTM (mean (SD)) & $\mathrm{N} / \mathrm{A}$ & $3.0(1.5)$ & $2.0(1.1)$ & 0.16 \\
Change in involvement in research have negative impact on midwife & $-0.2(0.8)$ & $-0.4(1.1)$ & $-0.6(1.1)$ & 0.54 \\
patient relationship (mean (SD)) & & $-0.4(1.4)$ & $-0.4(1.3)$ & 0.98 \\
$\begin{array}{l}\text { Change in confidence that TTM will reduce smoking (B and C) (mean (SD)) } \\
\text { Change in confidence that interventions will reduce smoking (mean (SD)) }\end{array}$ & $0.3(1.0)$ & $1.0(1.0)$ & $0.9(0.8)$ & 0.022 \\
$\begin{array}{l}\text { Change in \% of women in research trial expected to give up smoking } \\
\text { during pregnancy (mean (SD))† }\end{array}$ & $-7.0(14.5)$ & $13.2(20.4)$ & $6.9(27.6)$ & 0.010 \\
$\begin{array}{l}\text { Change in involvement in research change attitude to own or others } \\
\text { smoking (mean (SD)) }\end{array}$ & $0.1(0.4)$ & $-0.2(0.4)$ & $-0.2(0.5)$ & 0.021 \\
\hline
\end{tabular}

*All scored on a 5 point scale, so maximum difference is 5 points, unless indicated.

$\dagger$ Difference in \% expected to quit.

$\ddagger$ Analysis of variance for difference between means.

N/A, not applicable.

Outcomes at 30 weeks of pregnancy

Using all recruits in the denominator, the point prevalence of confirmed smoking cessation was $1.7 \%$ of women in arm A, $4.3 \%$ in arm B, and $5.7 \%$ in arm C. For sustained abstinence, these percentages were $1.4 \%, 2.6 \%$, and $3.1 \%$, respectively (table 4). Regardless of denominator or outcome, there were no significant differences between the arms. When arms B and $\mathrm{C}$ were combined, there was a significant benefit for self report and confirmed point prevalence of quitting, but not for 10 week abstinence (table 5 ).

\section{Outcomes at 10 days postnatal}

Using all recruits in the denominator, the point prevalence of confirmed smoking was 3.5\% of women in arm A, $4.7 \%$ in arm $\mathrm{B}$, and $8.1 \%$ in arm C. For sustained abstinence, these percentages were $1.0 \%, 3.0 \%$, and $2.8 \%$ respectively (table 6 ). There were no significant differences between the arms, except for the outcome of point prevalence of quitting with all non-dropouts and all women in the denominator. When arms $\mathrm{B}$ and $\mathrm{C}$ were combined, there was a significant benefit for confirmed point prevalence and sustained abstinence and self reported point prevalence of quitting, which depended on the denominator (table 7).

\section{Ancillary analyses}

In general, adjustment for differences in the baseline characteristics of women in the trial did not greatly alter the apparent effect of the intervention.

Women in arm A were less likely to complete a questionnaire and have a urine sample taken. This is shown in fig 2 for 10 days postnatal, although the effect was apparent at 30 weeks of pregnancy also. Given that non-responders were categorised as smokers, this would bias the results to favour arms

Table 4 Outcome at 30 weeks of pregnancy

\begin{tabular}{|c|c|c|c|c|c|c|c|c|c|}
\hline & \multicolumn{6}{|c|}{ Unadjusted } & \multicolumn{3}{|l|}{ Adjusted } \\
\hline & \multirow{2}{*}{$\begin{array}{l}\text { Arm A } \\
\% \\
\text { quitters }\end{array}$} & \multicolumn{2}{|l|}{ Arm B } & \multicolumn{2}{|l|}{ Arm C } & \multirow{2}{*}{$\begin{array}{l}\begin{array}{l}\text { Difference } \\
\text { between } \\
\text { arms }\end{array} \\
\chi^{2}, \mathrm{p}\end{array}$} & \multirow{2}{*}{$\frac{\text { Arm B }}{\text { OR }(95 \% \mathrm{Cl})}$} & \multirow{2}{*}{$\begin{array}{l}\text { Arm C } \\
\text { OR }(95 \% \mathrm{Cl})\end{array}$} & \multirow{2}{*}{$\begin{array}{l}\begin{array}{l}\text { Difference } \\
\text { between } \\
\text { arms }\end{array} \\
\chi^{2}, \mathrm{p}\end{array}$} \\
\hline & & $\begin{array}{l}\% \\
\text { quitters }\end{array}$ & OR $(95 \% \mathrm{Cl})$ & $\begin{array}{l}\text { \% } \\
\text { quitters }\end{array}$ & OR $(95 \% \mathrm{Cl})$ & & & & \\
\hline \multicolumn{10}{|c|}{$\begin{array}{l}\text { Self reported smoking } \\
\text { Sustained quit since } 20 \mathrm{w}\end{array}$} \\
\hline All followed up & 5.5 & 7.6 & $\begin{array}{l}1.41 \\
(0.61 \text { to } 3.27)\end{array}$ & 5.4 & $\begin{array}{l}0.98 \\
(0.41 \text { to } 2.34)\end{array}$ & $1.0,0.58$ & $\begin{array}{l}1.16 \\
(0.45 \text { to } 2.96)\end{array}$ & $\begin{array}{l}0.88 \\
(0.32 \text { to } 2.42)\end{array}$ & $0.4,0.83$ \\
\hline All non-dropouts & 4.1 & 6.6 & $\begin{array}{l}1.63 \\
(0.70 \text { to } 3.77)\end{array}$ & 4.8 & $\begin{array}{l}1.16 \\
(0.48 \text { to } 2.81)\end{array}$ & $1.5,0.47$ & $\begin{array}{l}1.25 \\
(0.50 \text { to } 3.12)\end{array}$ & $\begin{array}{l}1.09 \\
(0.41 \text { to } 2.93)\end{array}$ & $0.2,0.88$ \\
\hline All & 3.1 & 5.2 & $\begin{array}{l}1.72 \\
(0.75 \text { to } 3.96)\end{array}$ & 4.0 & $\begin{array}{l}1.30 \\
(0.55 \text { to } 3.09 \text { ) }\end{array}$ & $1.7,0.43$ & $\begin{array}{l}1.46 \\
(0.50 \text { to } 4.27)\end{array}$ & $\begin{array}{l}1.35 \\
(0.43 \text { to } 4.18)\end{array}$ & $0.5,0.78$ \\
\hline \multicolumn{10}{|l|}{ Point prevalence quit } \\
\hline All followed up & 6.4 & 10.3 & $\begin{array}{l}1.69 \\
(0.74 \text { to } 3.82)\end{array}$ & 10.4 & $\begin{array}{l}1.69 \\
(0.76 \text { to } 3.75)\end{array}$ & $1.9,0.38$ & $\begin{array}{l}1.48 \\
(0.60 \text { to } 3.68)\end{array}$ & $\begin{array}{l}1.73 \\
(0.69 \text { to } 4.30)\end{array}$ & $1.4,0.50$ \\
\hline All non-dropouts & 5.1 & 8.6 & $\begin{array}{l}1.77 \\
(0.83 \text { to } 3.77)\end{array}$ & 9.6 & $\begin{array}{l}1.98 \\
(0.95 \text { to } 4.15)\end{array}$ & $3.4,0.18$ & $\begin{array}{l}1.49 \\
(0.65 \text { to } 3.40)\end{array}$ & $\begin{array}{l}2.12 \\
(0.92 \text { to } 4.87 \text { ) }\end{array}$ & $3.1,0.21$ \\
\hline All & 3.7 & 7.1 & $\begin{array}{l}2.01 \\
(0.91 \text { to } 4.44)\end{array}$ & 7.7 & $\begin{array}{l}2.21 \\
\text { (1.02 to } 4.78)\end{array}$ & $4.3,0.12$ & $\begin{array}{l}1.85 \\
(0.78 \text { to } 4.39)\end{array}$ & $\begin{array}{l}2.39 \\
(1.01 \text { to } 5.67)\end{array}$ & $4.0,0.14$ \\
\hline \multicolumn{10}{|c|}{ Cotinine confirmed } \\
\hline \multicolumn{10}{|c|}{ Sustained quit since 20 weeks gestation } \\
\hline All followed up & 2.4 & 3.8 & $\begin{array}{l}1.57 \\
(0.46 \text { to } 5.30)\end{array}$ & 4.1 & $\begin{array}{l}1.72 \\
(0.53 \text { to } 5.59)\end{array}$ & $0.8,0.66$ & $\begin{array}{l}1.30 \\
(0.34 \text { to } 4.96)\end{array}$ & $\begin{array}{l}1.89 \\
(0.49 \text { to } 7.28)\end{array}$ & $0.9,0.62$ \\
\hline All non-dropouts & 1.8 & 3.3 & $\begin{array}{l}1.81 \\
(0.54 \text { to } 6.11)\end{array}$ & 4.0 & $\begin{array}{l}2.21 \\
(0.68 \text { to } 7.15)\end{array}$ & $1.8,0.42$ & $\begin{array}{l}1.51 \\
(0.41 \text { to } 5.60)\end{array}$ & $\begin{array}{l}2.43 \\
(0.65 \text { to } 9.07)\end{array}$ & $1.8,0.40$ \\
\hline All & 1.4 & 2.6 & $\begin{array}{l}1.92 \\
(0.57 \text { to } 6.44)\end{array}$ & 3.1 & $\begin{array}{l}2.27 \\
(0.70 \text { to } 7.31)\end{array}$ & $1.9,0.39$ & $\begin{array}{l}1.77 \\
(0.49 \text { to } 6.38)\end{array}$ & $\begin{array}{l}2.62 \\
(0.74 \text { to } 9.25)\end{array}$ & $2.3,0.33$ \\
\hline \multicolumn{10}{|l|}{ Point prevalence quit } \\
\hline All followed up & 3.1 & 6.1 & $\begin{array}{l}2.08 \\
(0.73 \text { to } 5.95)\end{array}$ & 7.4 & $\begin{array}{l}2.55 \\
(0.93 \text { to } 7.02)\end{array}$ & $3.3,0.19$ & $\begin{array}{l}1.60 \\
(0.51 \text { to } 5.06)\end{array}$ & $\begin{array}{l}2.80 \\
(0.90 \text { to } 8.73)\end{array}$ & $3.5,0.17$ \\
\hline All non-dropouts & 2.3 & 4.9 & $\begin{array}{l}2.20 \\
(0.76 \text { to } 6.36)\end{array}$ & 7.2 & $\begin{array}{l}3.27 \\
(1.20 \text { to } 8.97)\end{array}$ & $5.4,0.066$ & $\begin{array}{l}1.77 \\
(0.57 \text { to } 5.48)\end{array}$ & $\begin{array}{l}3.76 \\
(1.23 \text { to } 11.48)\end{array}$ & $6.1,0.047$ \\
\hline All & 1.7 & 4.3 & $\begin{array}{l}2.53 \\
(0.89 \text { to } 7.19)\end{array}$ & 5.6 & $\begin{array}{l}3.34 \\
\text { (1.22 to } 9.11)\end{array}$ & $5.5,0.062$ & $\begin{array}{l}2.03 \\
(0.68 \text { to } 6.11)\end{array}$ & $\begin{array}{l}3.45 \\
(1.17 \text { to } 10.14)\end{array}$ & $5.3,0.072$ \\
\hline
\end{tabular}


Table 5 Outcome at 30 weeks of pregnancy, combining arms $B$ and $C$ versus arm $A$

\begin{tabular}{|c|c|c|}
\hline & Unadjusted OR (95\% CI) & Adjusted OR $(95 \% \mathrm{Cl})$ \\
\hline \multicolumn{3}{|c|}{ Self reported smoking } \\
\hline \multicolumn{3}{|c|}{ Sustained quit since 20 weeks gestation } \\
\hline All followed up & $1.18(0.64$ to 2.16$)$ & $1.02(0.51$ to 2.03$)$ \\
\hline All non-dropouts & $1.39(0.75$ to 2.55$)$ & $1.17(0.60$ to 2.30$)$ \\
\hline All & $1.50(0.83$ to 2.74$)$ & $1.41(0.65$ to 3.06$)$ \\
\hline \multicolumn{3}{|l|}{ Point prevalence quit } \\
\hline All followed up & 1.69 (0.95 to 2.99$)$ & $1.60(0.84$ to 3.05$)$ \\
\hline All non-dropouts & $1.88(1.11$ to 3.18$)$ & $1.77(0.99$ to 3.19$)$ \\
\hline All & $2.11(1.21$ to 3.67$)$ & $2.11(1.14$ to 3.88$)$ \\
\hline \multicolumn{3}{|l|}{ Cotinine confirmed } \\
\hline \multicolumn{3}{|c|}{ Sustained quit since 20 weeks gestation } \\
\hline All followed up & $1.65(0.71$ to 3.84$)$ & $1.56(0.60$ to 4.05$)$ \\
\hline All non-dropouts & 2.01 (0.86 to 4.67$)$ & 1.91 (0.76 to 4.84$)$ \\
\hline All & $2.09(0.90$ to 4.85$)$ & $2.16(0.88$ to 5.31$)$ \\
\hline \multicolumn{3}{|l|}{ Point prevalence quit } \\
\hline All followed up & 2.31 (1.12 to 4.80$)$ & 2.12 (0.95 to 4.77$)$ \\
\hline All non-dropouts & 2.71 (1.31 to 5.63$)$ & 2.59 (1.17 to 5.74$)$ \\
\hline All & $2.92(1.42$ to 6.03$)$ & $2.66(1.23$ to 5.75$)$ \\
\hline
\end{tabular}

$\mathrm{B}$ and $\mathrm{C}$. We modelled the potential importance of this with all recruits in the denominator for point prevalence of quitting. For this model, we assumed that the quit rate among those not followed up was that observed among those in their arm of the trial. We assumed that the whole study average "failure to disclose" rate for cotinine applied to these women. Under these assumptions, the point estimates for the odds ratios for arms B and $\mathrm{C}$ versus arm A were 1.67 and 1.55 at 30 weeks gestation. The corresponding calculated ones were 2.53 and 3.54 (table 4). At 10 days postnatal, the odds ratios under these assumptions were 1.19 and 1.79 for arms $\mathrm{B}$ and $\mathrm{C}$, and the corresponding calculated ones were 1.34 and 2.42 (table 6).
Only two other studies have examined the benefit of Pro-Change materials versus brief written or verbal advice in smoking cessation..$^{30}$ Using all enrolled participants in the denominator, meta-analyses of these three studies produced an odds ratio of 1.42 (95\% CI 1.07 to 1.88 ) for self report sustained quitting, with no evidence of heterogeneity.

\section{DISCUSSION}

\section{Principal findings}

This study has shown that women using self help interventions based on the stages of change model were approximately twice as likely to stop smoking as those given routine smoking

\section{Table 6 Outcome at 10 days postnatally}

\begin{tabular}{|c|c|c|c|c|c|c|c|}
\hline \multicolumn{5}{|c|}{ Unadjusted } & \multicolumn{3}{|l|}{ Adjusted } \\
\hline Arm A & Arm B & Arm C & & $\begin{array}{l}\text { Difference } \\
\text { between } \\
\text { arms }\end{array}$ & Arm B & Arm C & $\begin{array}{l}\text { Difference } \\
\text { between } \\
\text { arms }\end{array}$ \\
\hline $\begin{array}{l}\% \\
\text { quitters }\end{array}$ & $\begin{array}{l}\% \\
\text { quitters OR }(95 \% \mathrm{Cl})\end{array}$ & $\begin{array}{l}\% \\
\text { quitters }\end{array}$ & OR $(95 \% \mathrm{Cl})$ & $\chi^{2}, p$ & OR $(95 \% \mathrm{Cl})$ & OR $(95 \% \mathrm{Cl})$ & $\chi^{2}, p$ \\
\hline
\end{tabular}

Self reported smoking

Sustained quit since 30 weeks gestation

All followed up 5.9

All non-dropouts

All

oint prevalence quit

All followed up

All non-dropouts

All

10.8

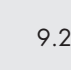

Cotinine confirmed

$\begin{array}{cc}\text { Sustained quit since } & 30 \text { weeks gestation } \\ \text { All followed up } & 1.6\end{array}$

All non-dropouts

All

Point prevalence quit

All followed up

All non-dropouts

All
5.1

$$
3.8
$$

1.16

(0.52 to 2.60 )

1.23

(0.55 to 2.74$)$

$4.9 \quad 1.31$

(0.59 to 2.90 )

1.11

(0.60 to 2.07 )

1.18

(0.64 to 2.18 )

1.25

(0.68 to 2.30 )

2.60

$(0.69$ to 9.75$)$

2.74

$(0.73$ to 10.26$)$

$\begin{array}{lll}1.0 \quad 3.0 \quad & 2.90 \\ & & (0.78 \text { to } 10.82)\end{array}$

$\begin{array}{lll}1.0 \quad 3.0 \quad & 2.90 \\ & & (0.78 \text { to } 10.82)\end{array}$

$\begin{array}{lll}4.5 & 5.4 \quad 1.22\end{array}$

$(0.43$ to 3.40$)$

1.30

10.52 to 3.23

4.6

3.5

$4.7 \quad 1.34$

(0.54 to 3.31 )

$0.2,0.90$

1.11

1.16

(0.46 to 2.70 ) $\quad(0.48$ to 2.80 )

$0.6,0.74$

1.11

1.05

$0.40,0.84$

(0.46 to 2.68$) \quad(0.43$ to 2.54$)$

$\begin{array}{lll}0.8,0.68 & 1.18 & 1.09\end{array}$

(0.50 to 2.76$) \quad(0.47$ to 2.52$)$

$0.0,0.98$

$0.1,0.93$

$\begin{array}{llll}4.6,0.099 & 1.04 & 1.53 & 1.6,0.44\end{array}$

(0.48 to 2.27$) \quad(0.72$ to 3.22$)$

$\begin{array}{lll}6.9,0.032 & 1.06 & 1.78 \\ & (0.50 \text { to } 2.27) & (0.86 \text { to } 3.70)\end{array}$

$6.9,0.032 \quad 1.11 \quad 1.79$

(0.54 to 2.27 ) (0.91 to 3.54 )

$3.1,0.22$

$3.4,0.18$

(1.15 to 3.50$)$

$3.7 \quad 2.34$

(0.63 to 8.78 )

$3.6 \quad 2.65$

$(0.71$ to 9.93$)$

$2.8 \quad 2.72$

(0.73 to 10.17 )

$\begin{array}{lll}2.1,0.35 & 1.82 & 1.54\end{array}$

(0.41 to 8.03 ) (0.33 to 7.13

$2.01 \quad 1.85$

$2.5,0.29$

$(0.46$ to 8.82$) \quad(0.41$ to 8.42$)$

$\begin{array}{lll}2.7,0.26 & 2.32 & 1.94\end{array}$

(0.58 to 9.33 ) (0.47 to 8.04 )

$9.4 \quad 2.21$

(0.85 to 5.71 )

$10.7 \quad 2.46$

(1.06 to 5.72 )

$8.1 \quad 2.42$

(1.05 to 5.57 ) $\begin{array}{lll}3.3,0.19 & 1.18 & 2.32\end{array}$

(0.33 to 4.23 ) (0.69 to 7.84 )

$\begin{array}{llll}5.3,0.073 & 1.16 & 2.65\end{array}$

(0.32 to 4.27$) \quad(0.77$ to 9.16$)$

$5.0,0.082 \quad 1.19$
$0.62,0.73$

$0.9,0.64$

$1.42,0.49$

$2.3,0.32$

$3.0,0.23$

$2.7,0.26$ 
Table 7 Outcome at 10 days postnatally, combining arms $B$ and $C$ versus arm $A$

\begin{tabular}{|c|c|c|}
\hline & Unadjusted OR $(95 \% \mathrm{Cl})$ & Adjusted OR $(95 \% \mathrm{Cl})$ \\
\hline \multicolumn{3}{|c|}{ Self reported smoking } \\
\hline \multicolumn{3}{|c|}{ Sustained quit since 30 weeks gestation } \\
\hline All followed up & 1.18 (0.67 to 2.07$)$ & $1.14(0.61$ to 2.12$)$ \\
\hline All non-dropouts & 1.30 (0.74 to 2.27$)$ & 1.08 (0.58 to 2.01$)$ \\
\hline All & 1.35 (0.78 to 2.36$)$ & 1.13 (0.62 to 2.06$)$ \\
\hline \multicolumn{3}{|l|}{ Point prevalence quit } \\
\hline All followed up & 1.41 (0.93 to 2.15$)$ & $1.27(0.74$ to 2.18$)$ \\
\hline All non-dropouts & 1.56 (1.03 to 2.37$)$ & 1.39 (0.82 to 2.35$)$ \\
\hline All & 1.62 (1.07 to 2.44$)$ & 1.43 (0.87 to 2.34$)$ \\
\hline \multicolumn{3}{|l|}{ Cotinine confirmed } \\
\hline \multicolumn{3}{|c|}{ Sustained quit since 30 weeks gestation } \\
\hline All followed up & 2.47 (0.97 to 6.28$)$ & 1.67 (0.58 to 4.87$)$ \\
\hline All non-dropouts & $2.70(1.06$ to 6.86$)$ & $1.93(0.67$ to 5.56$)$ \\
\hline All & 2.81 (1.11 to 7.13$)$ & $2.13(0.79$ to 5.75$)$ \\
\hline \multicolumn{3}{|l|}{ Point prevalence quit } \\
\hline All followed up & 1.68 (0.83 to 3.37$)$ & $1.68(0.70$ to 4.06$)$ \\
\hline All non-dropouts & 1.83 (0.99 to 3.40$)$ & 1.79 (0.73 to 4.39$)$ \\
\hline All & 1.85 (1.00 to 3.41$)$ & $1.71(0.75$ to 3.89$)$ \\
\hline
\end{tabular}

cessation advice by midwives. Where the effects were significant, this was often borderline, and many analyses were not significant. The effect of the stage based approach was greater for cotinine confirmed smoking cessation than self reported, and greater in those women using the computer programme rather than the manual alone. Smoking cessation increased incrementally between the three trial arms with cessation being higher in arm B than in arm A, and in arm C than in arm B. However the differences are small and not significant. This pattern replicates that found in another study. ${ }^{31}$ Some of the advantage of the stages of change arms could have occurred because midwives in these arms were more enthusiastic and consequently followed the research protocol more closely than did midwives offering routine care.

\section{Strengths and weaknesses of the study}

This trial was set in routine midwifery practice and is therefore generalisable to current UK midwifery practice. The design of the randomised controlled trial was robust and the analysis of outcome data was rigorous. Data from the extra general practices added to trial arms A and B to boost recruitment towards the end of the field work, were analysed both separately and inclusive of the main trial data, and no significant effect was found from including these practices. Difficulty
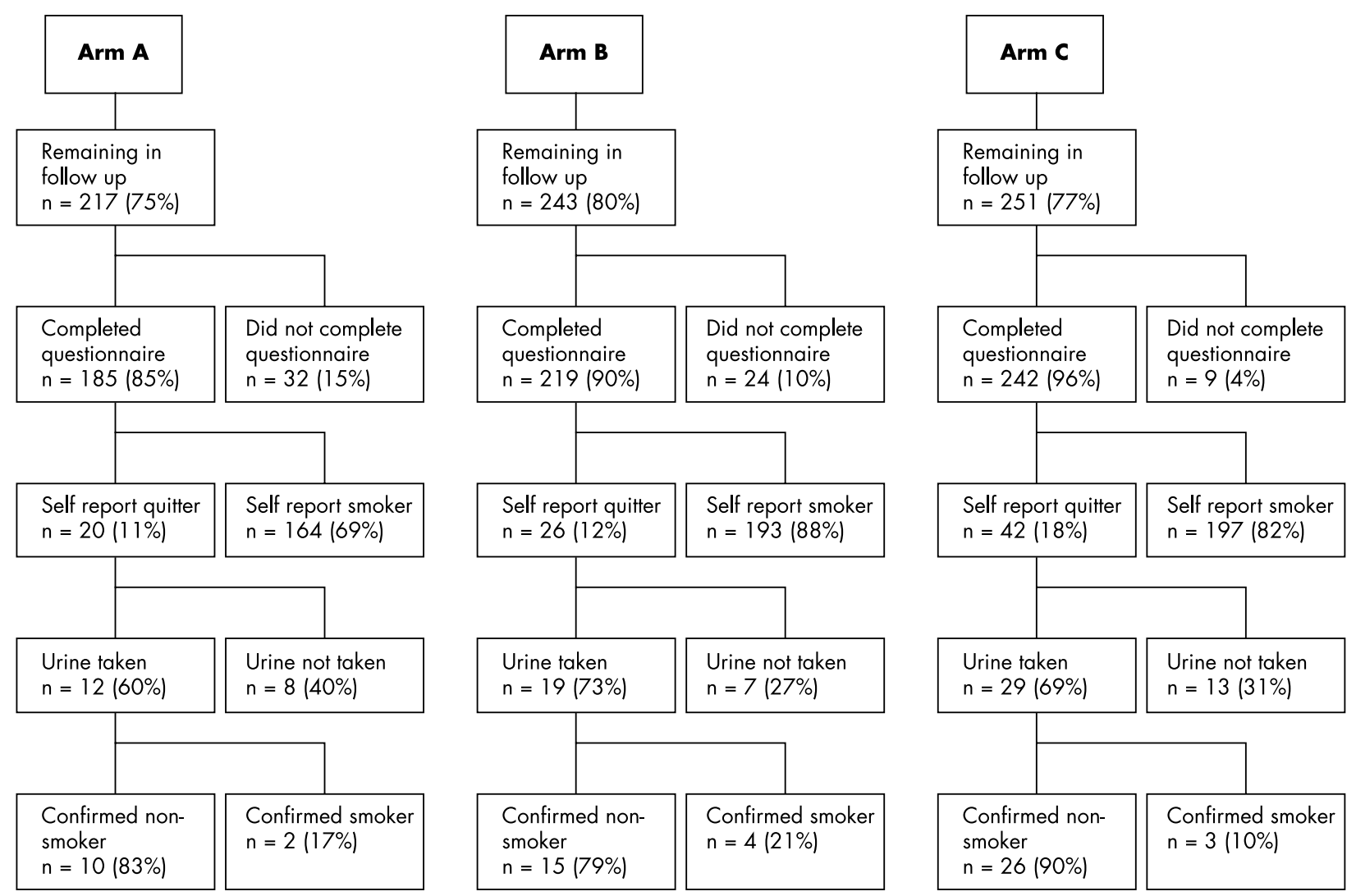

Figure 2 Flow diagram of attempts to confirm smoking status at 10 days post natal contact. 
in recruiting was a weakness of this trial, but this is a common feature of trials dependent on health practitioner recruitment, $^{32}{ }^{33}$ and probably reflects current workload overburden in midwifery. Towards the end of the fieldwork we resorted to incentives for recruitment but there is no evidence that this influenced recruitment, nor that it had any effect on the intrinsic likelihood of stopping smoking. There was considerable variation in the length of time taken to recruit to the three trial arms, with recruitment to trial arm C, the computer intervention, finishing some six months ahead of recruitment to the other two arms. However, there is no evidence to suggest that this effected outcome.

This trial recruited only women who were smokers at the time of booking their pregnancy ( $<20$ weeks). The majority of women who stop smoking with pregnancy do so either in the period before conception or in the early stages of pregnancy. ${ }^{34}$

Moreover, interventions appear to be more successful for lighter smokers than for committed heavier smokers, such as were recruited to our trial. ${ }^{35}$ By exempting recent ex-smokers we inevitably recruited women who were more resistant to change, and thus the cessation rate in the control and intervention groups is lower than in many other trials that included recent ex-smokers. ${ }^{1}$ This makes it harder to detect relative differences in the quit rate between arms. Nevertheless, the point estimate for smoking cessation in late pregnancy is slightly higher than that found in the meta-analysis from other trials in pregnancy reported in the Cochrane review.

Research indicates that training midwives in delivering smoking cessation interventions does not increase effective outcomes, ${ }^{32}{ }^{36}{ }^{37}$ although there is a generally reported increase in process variables such as raising the issue of smoking and delivering cessation interventions. It seems possible, in our trial, that there is a training effect. Although there was no important difference in baseline characteristics between midwives in the three trial arms, midwives in the two intervention arms scored more positively than midwives in the control arm on confidence in delivering the intervention and confidence that the intervention would reduce smoking. Furthermore, midwives in the computer intervention arm, despite having the most time consuming intervention to deliver, completed recruitment six months ahead of the other two arms and recruited the highest proportion of eligible women, suggesting greater enthusiasm. This could not be attributed to training as midwives in both intervention arms attended the same training. Our informal observations were that it made no difference to arm A midwives to know they were in the control group, and that arm $\mathrm{C}$ had the greatest belief in the efficacy of their intervention and their confidence may have been transmitted to women and influenced the relative success in stopping smoking. This training effect concurs with evidence that counselling from a smoking cessation specialist together with written support materials is effective in aiding cessation. ${ }^{179}$

For all three trial arms, at 30 weeks of pregnancy and at 14 days post-natal, self reported smoking cessation was greater, by around $50 \%$, than validated cessation, partly because of failure to collect urine, and partly because some women's cotinine levels suggested continuing smoking. It is possible that when a pregnant smoker has reduced her cigarette consumption or adopted spasmodic, rather than regular, smoking behaviour her self concept is that of a "non-smoker". There is some indication that pregnant women are reluctant to describe themselves as smokers in the context of obstetric care and especially after smoking cessation counselling. ${ }^{24}{ }^{38}$ To assist targeted interventions, this issue bears further investigation.

\section{Policy implications}

The best estimate of the effectiveness of the Pro-Change materials delivered by midwives and tested in this trial is that

\section{What this paper adds}

Other studies have shown that brief smoking cessation interventions delivered by midwives are ineffective. Interventions based on the transtheoretical model (TMM) look promising but there are no current trials of such interventions in pregnant smokers. Midwives delivered one of three interventions. The control arm received current standard care, and the two intervention arms received interventions based on the TTM-a stage based, self help manual-and the stage based manual plus an interactive computer program. The interventions were significantly more effective than current standard care, but the absolute benefit was small with only $3 \%$ of women in the intervention group achieving sustained confirmed cessation.

they approximately double the quit rate over that which would be achieved by midwives' current practice. However, the effect is small and the public health impact negligible. At 30 weeks gestation and at 10 days postnatal, only about $3 \%$ of the intervention groups achieved sustained cessation, with numbers needed to treat of 67 ( 30 weeks of gestation) and 53 ( 10 weeks postnatal) for one additional woman to achieve sustained confirmed cessation. Across the range of outcomes and denominators presented, we estimate that the quit rate approximately doubled in the intervention arms, which is what a meta-analysis of previous smoking cessation programmes in pregnancy found, summarised in the Cochrane review. ${ }^{1}$ Currently, most pregnant smokers do not recall receiving smoking cessation advice from a midwife ${ }^{4}$ and midwives cannot deliver effective smoking cessation interventions in routine practice. ${ }^{13} 32{ }^{37}$ Our trial showed that an interactive computer programme, backed up by complimentary self help materials and a supportive feedback letter, delivered in the course of routine midwifery practice has a small effect, and that midwives were confident about using the intervention and in its potential effect. Delivering the Pro-Change interventions was costly and resource intensive in terms of midwives' training, time, and purchase of capital equipment. An alternative system could involve midwives routinely giving brief advice for smoking cessation and referring on women to the new network of UK smoking cessation services. A third option is to assist women to stop smoking before they ever reach the midwifery service. Smoking in pregnancy is currently a problem for which there is no good currently available solution.

\section{ACKNOWLEDGEMENTS}

We are especially grateful to Robert Lancashire for his IT expertise and help with data analysis, and to Helen Evans who worked as the trial coordinator on this project. Our thanks too to the West Midlands Regional Levies Board, which funded the research trial, and to all other members of the Behavioural Epidemiology Research Group who assisted at sometime with this project. The project would not have been possible without the hard work of all 100 general practices and 182 community midwives.

\section{Authors' affiliations}

T Lawrence, P Aveyard, Olga Evans, K K Cheng, The Department of Public Health and Epidemiology, University of Birmingham, Birmingham, UK

\section{REFERENCES}

1 Lumley J, Oliver S, Waters E. Interventions for promoting smoking cessation during pregnancy (Cochrane Review). In: The Cochrane Library, Issue 3, 2002. Oxford: Update Software.

2 Baric L, MacArthurC, Sherwood M. A study of health education aspects of smoking in pregnancy. Int J Health Educ 1976;19:1-17.

3 Brooker S, Wands S, Paice K. Infant feeding survey 2000. London, HMSO, 2001. 
4 Bolling K, Owen L. Smoking and pregnancy: a survey of knowledge, attitudes and behaviour. London: Health Education Authority, 1999.

5 Tappin DM, Lumsden MA, Mclntyre D, et al. A pilot study to establish a randomised trial methodology to test the efficacy of a behavioural intervention. Health Educ Res 2000;15:491-502.

6 Ershoff DH, Quinn VP, Boyd NR, et al. The Kaiser Permanente prenatal smoking-cessation trial: when more isn't better, what is enough? Am J Prev Med 1999;17:161-8.

7 Orleans CT, Barker DC, Kaufman NJ, et al. Helping pergnant smokers quit: meeting the challenge in the next decade. Tobacco Control 2000;9(suppl III): iii6-11).

8 West R, McNeill A, Raw M. Smoking cessation guidelines for health professionals: an update. Thorax 2000;55:987-99.

9 Melvin C, Dolan-Mullan P, Windsor R, et al. Recommended cessation counselling for pregnant women who smoke: a review of the evidence. Tobacco Control 2002;9(suppl III):iii80-4.

10 Owen L, Penn G. Smoking and pregnancy: a survey of knowledge attitudes and behaviour 1992 -1999. London: Health Education Authority, 2000.

11 Cooke M, Mattick RP, Barclay L. Predictors of brief smoking intervention in a midwifery setting. Addiction 1996;91:1715-25.

12 Hajek P, West R, Lee A, et al. Randomized controlled trial of a midwife-delivered brief intervention in pregnancy. Addiction 2001;96:485-94.

13 Lancaster T, Silagy C, Fowler G. Training health professionals in smoking cessation (Cochrane Review). In: The Cochrane Library, Issue 3 2002. Oxford: Update Software.

14 Nagle A, Schofield M, Redman S. Australian nurses' smoking behaviour, knowledge and attitudes towards providing smoking cessation care to their patients. Health Prom Int 1999;14:133-44.

15 Prochaska JO, Diclemente CC, Velicer WF, et al. Standardized, individualized, interactive, and personalized self-help programs for smoking cessation. Health Psychol 1993;12:399-405.

16 Velicer WF, Prochaska JO, Fava JL, et al. Interactive versus noninteractive interventions and dose-response relationships for stage-matched smoking cessation programs in a managed care setting Health Psychol 1999;18:21-8

17 Prochaska JO, Velicer WF, Fava JL, et al. Evaluating a population-based recruitment approach and a stage-based expert system intervention for smoking cessation. Addict.Behav 2001 :26:583-602.

18 Prochaska JO, Velicer WF, Fava JL, et al. Counselor and stimulus control enhancements of a stage-matched expert system intervention for smokers in a managed care setting. Prev Med 2001;32:22-32.

19 Aveyard P, Cheng KK, Almond J, et al. A cluster-randomised controlled trial of an expert system based on the transtheoretical ("stages of change") model for smoking prevention and cessation in schools. BM 1999;319:948-53

20 Aveyard P, Sherratt E, Almond J, et al. The change-in-stage and updated smoking status results from a cluster-randomized trial of smoking prevention and cessation using the transtheoretical model among British adolescents. Prev Med 2001;33:313-24.

21 Roland M, Torgerson DJ. Understanding controlled trials. What are pragmatic trials? BM 1998;316:285

22 Jarvis MJ, Tunstall-Pedoe H, Feyerabend C, et al. Comparison of tests used to distinguish smokers from non-smokers. Am J Public Health 1987;77:1435-8.

23 Cope G, Nayyar P, Holder R, et al. A simple near-patient test for nicotine and its metabolites in urine to assess smoking habit. Clin Chim Acta 1996:256:135-49.

24 Kendrick JS, Zahniser SC, Miller N, et al. Integrating smoking cessation into routine public prenatal care: the smoking cessation in pregnancy project. Am J Public Health 1995;85:217-22.

25 Prochaska JO, Diclemente CC, Velicer WF, et al. Standardized, individualized, interactive, and personalized self-help programs for smoking cessation. Health Psychol 1993;12:399-405.

26 Velicer WF, Prochaska JO, Bellis JM, et al. An expert system intervention for smoking cessationn. Addict Behav 1993;18:269-90.

27 Goldstein H, Rasbash J, Plewis I, et al. A user's guide to MLwiN. London: Institute of Education, 1998.

28 Foster K, Lader D, Cheesebrough S. Infant feeding 1995. London: Office for National Statistics, 1997.

29 May S, West R. Do social support interventions ("buddy systems") aid smoking cessation? A review. Tobacco Control 2000;9:415-22.

30 Aveyard P, Griffin C, Lawrence PT, et al. A controlled trial of an expert system and self-help manual intervention based on the stages of change versus standard self-help materials in smoking cessation. Addiction (in press).

31 Prochaska JO, Diclemente CC, Velicer WF, et al. Standardized, individualized, interactive, and personalized self-help programs for smoking cessation. Health Psychol 1993;12:399-405.

32 Hajek P, West R, Lee A, et al. Randomized controlled trial of a midwife-delivered brief intervention in pregnancy. Addiction 2001;96:485-94.

33 Wisborg K, Henriksen TB, Secher NJ. A prospective intervention study of stopping smoking in pregnacy in a routine antenatal care setting. $\mathrm{Br} J$ Obstet Gynaecol 1998;11:1171-6.

34 Baric L, Macarthur C. Health norms in pregnancy. Br J Prev Soc Med 1977;31:30-8.

35 Ershoff DH, Mullen PD, Quinn VP. A Randomized trial of a serialized self-help smoking cessation program for pregnant women in an $\mathrm{HMO}$. Am J Public Health 1989;79: 182-7.

36 Owen L. Smoking and pregnancy: the role of midwives. The Practising Midwife 1999;2:14-5.

37 Cooke M, Mattick RP, Barclay L. Predictors of brief smoking intervention in a midwifery setting. Addiction 1996;91:1715-25.

38 Windsor R, Lowe JB, Perkins LL, et al. Health education for pregnant smokers: its behavioral impact and cost benefit. Am J Public Health 1993;83:201-6. 